\title{
Reflexiones sobre la legitimidad ética del Estado de derecho
}

\author{
Nuria Cordero Ramos y José E. Palacios Esteban'
}

Resumen: El artículo responde a la necesidad de reflexionar sobre la importancia de la legitimidad del Estado de Derecho. La comprensión moral en la que éste se legitima, reclama la construcción de una ética pública en el actual contexto de pluralismo cultural, garantizando exigencias y valores básicos que hagan posible una convivencia pacífica. De esta forma, corresponde a los poderes públicos la obligación de procurar una formación ciudadana, respetuosa con las diferencias, que reconozca y capacite como sujetos morales a todos los miembros de la sociedad. Asimismo, se pretende advertir sobre los riesgos que corre dicha legitimidad, ante estrategias políticas que defienden la utilización de procedimientos violentos para salvaguardar la seguridad nacional. Se hace ver, cuál es el trasfondo ideológico que subyace a la argumentación que justifica los discursos de los responsables políticos que se citan. Todo ello refuerza nuestra convicción acerca de la necesidad de una adecuada formación de la ciudadanía.

Palabras clave: Ética pública, Formación ciudadana, Estado de Derecho, Seguridad Nacional, Dignidad Humana, Derechos Humanos.

Fecha de recepción: 9 de diciembre de 2010.

Fecha de aceptación definitiva: 27 de junio de $20 \mathrm{II}$.

\footnotetext{
'Profesores Titulares de Trabajo Social; miembros del "Seminario de Ética y Acción Social". Universidad Pablo de Olavide
} 


\section{Reflections on the ethical legitimacy of the rule of law}

\begin{abstract}
The article responds to the need to reflect on the importance of the legitimacy of the rule of law. The moral understanding on which this legitimacy is based clamours for the development of public ethics in the current context of cultural pluralism, ensuring the basic needs and values that enable peaceful coexistence. Thus, the duty of forming citizens corresponds to appropriate public authorities who must provide training that respects differences, that recognizes all members of society and enables them to be moral subjects. Moreover italso seeks to warn about the risks that such legitimacy runs when faced with political strategies that defend the use of violent procedures to safeguard national security. It reveals the ideological background behind the argument justifying the speeches of politicians who are quoted. All this reinforces our belief in the need for adequate formation of citizens.
\end{abstract}

Keywords: public ethics, citizenship, rule of law, National Security, Human Dignity, Human Rights.

\section{Réflexions sur la légitimité éthique de l'état de droit}

Résumé: Cet article répond à la nécessité de réflexion sur l'importance de la légitimité de l'État de Droit. La compréhension morale sur laquelle celui-ci est légitimé nécessite de la construction d'une éthique publique dans le contexte actuel de pluralisme culturel, en garantissant les exigences et les valeurs essentielles qui rendent possible une coexistence pacifique. De cette façon, les pouvoirs publics ont l'obligation de procurer une formation citoyenne, respectueuse des différences, qui reconnaisse et permette à tous les membres de la société de devenir de sujets moraux. De même, l'auteur nous avertit des dangers que court cette légitimité face à des stratégies politiques qui défendentl'utilisation de procédures violentes pour sauvegarder la sécurité nationale. Il nous montre également quel estle base idéologique présente dans l'argumentation qui justifie les discours des responsables politiques nommés. Tout cela renforce notre conviction sur la nécessité d'une adéquate formation de la citoyenneté.

Mots clés: Éthique publique, Formation citoyenne, État de Droit, Sécurité Nationale, Dignité Humaine, Droits de l'Homme.

\section{Introducción}

La tesis que desarrollamos en este artículo se refiere a la necesidad de reflexionar sobre la importancia de la legitimidad del Estado de Derecho. Para ello hemos organizado nuestra línea argumental en cuatro partes:

En la primera, planteamos cómo la legitimidad del Estado de Derecho va más allá de las inclinaciones innatas y del proceso de moralización de cada individuo. Se 
trata de una legitimidad basada en el análisis contextual del pluralismo moral para, a partir de ahí, tratar de buscar acuerdos comunes sobre los principios y normas en orden a una convivencia pacífica que garantice la respuesta a exigencias morales básicas para el común de las personas. Reconocer la existencia de un marco regulativo que explicita los derechos y responsabilidades de los ciudadanos nos conduce a pensar en la existencia de una ética pública como soporte del Estado de Derecho

En la segunda parte del trabajo desarrollamos los argumentos que justifican la importancia de una formación cívica capaz de desarrollar la autonomía de las personas desde una reflexión crítica a los valores de la moral dominante. La fundamentación de la formación para la ciudadanía debe basarse en el respeto y en la responsabilidad de los sujetos morales del Estado de Derecho.

En la tercera, analizamos estrategias políticas que vulneran la legitimidad del Estado de Derecho, fundamentadas sobre la necesidad de salvaguardar la seguridad nacional. Nos referimos, concretamente, a las justificaciones políticas en relación con la utilización de procedimientos violentos, incompatibles con el Estado de Derecho, para proteger "aquellas vidas que hay que salvar" frente a "aquellas que han de ser sacrificadas" bajo la premisa del Bien Común. Expresamos nuestra preocupación sobre las conexiones entre argumentos particulares de responsables políticos, como el ex Presidente Bush y el ex Presidente Gónzalez, con estrategias de políticas neoliberales que tratan de imponerse globalmente y de forma hegemónica.

Finalmente, intentamos recoger las principales conclusiones que a nuestro parecer se decantan de las reflexiones precedentes.

\section{La legitimidad del Estado de Derecho}

En la implantación del imperio de la ley como función del Estado de Derecho frente a decisiones impredecibles y arbitrarias, nuestra Constitución fundamenta su legitimidad en los Derechos Humanos, los cuales traducen a leyes positivas las exigencias morales previas de la dignidad humana. Así lo entiende el profesor Laporta (2007) en la obra dedicada a este tema: "incluso si suponemos (erróneamente) que lo que llamamos imperio de la ley es un conjunto de exigencias normativas e institucionales meramente jurídicas, la justificación de las normas del derecho desde el derecho mismo tiene un alcance muy limitado; su verdadera justificación tiene que ir, por razones lógicas, más allá del derecho. Y más, claro 
está, cuando se trata de normas jurídicas que, como aquellas que articulan las demandas del imperio de la ley, suelen estar situadas en los escalones normativos jerárquicamente superiores en rango del ordenamiento jurídico; es decir, suelen ser normas constitucionales... Y ¿̇qué otra cosa puede ser eso que sirve de base a la justificación de normas jurídicas sino principios y valores morales?"2.

Esta comprensión de la ética pública, y la disposición a obrar de acuerdo con ella, tienen unas características que, por sus importantes consecuencias para nuestra convivencia, bien merece la pena destacar.

Dicha comprensión no responde a inclinaciones innatas en los seres humanos. No podemos perder de vista que nuestra conducta moral no es un mero reflejo pasivo de la constitución biológica. Sin duda, es imposible crear esa conducta desde uno mismo con total independencia de los límites vitales. Pero cabe definirla en mayor o menor medida, siempre en diálogo abierto a un horizonte de emancipación individual y colectiva, dentro de un contexto de libertad casi siempre ejercida con riesgos y valentía y de una racionalidad que aprende del pasado, interpreta el presente y proyecta el futuro, diferenciándose significativamente unas conductas de otras. Es lo que nos dice no sólo la forma que tenemos de entendernos a nosotros mismos, sino el testimonio y la confirmación de la experiencia histórica.

En un reciente artículo de Adela Cortina (2010), en el que critica la introducción de la "neuroética" como la disciplina que promete explicar y tratar adecuadamente la conducta moral, concluye así: "Si es verdad que la tendencia de ciertos códigos inscritos en el cerebro nos llevan a interesarnos en mayor medida por los problemas personales que por los impersonales, a reaccionar positivamente ante los cercanos y semejantes y negativamente ante los extraños, entonces en vez de generar sentimientos de culpabilidad ante tales reacciones más vale preguntar si queremos fomentar esas tendencias o, por el contrario, debilitarlas, si es ése el proyecto moral que queremos impulsar o si nos importa el derecho de todos y cada uno de los seres humanos. Dado que los sentimientos son cultivables, una razón cordial impulsaría, no a estar lamentando continuamente reacciones inmediatas de las que después nos avergonzamos, sino a cultivar emociones y razón en el sentido que elijamos como moralmente superior. Ahora bien, en el diseño de ese sentido que elijamos como moralmente superior, y además con pretensión universal, me temo que no son las neurociencias las que nos van a dar la respuesta" ${ }^{3 .}$

${ }^{2}$ F. J. LAPORTA (2007:18).

${ }^{3}$ A. Cortina (2010: 143, s.). 
Nuestra comprensión moral de la convivencia y del consiguiente Estado de Derecho tampoco es fruto de revelaciones o intuiciones y para alcanzarla no ofrece garantías suficientes la socialización en los valores de las tradiciones y la comunidad de pertenencia, aunque sea necesaria para iniciarnos en la "moralidad". Dicha socialización es necesaria para aprender a comportarnos moralmente, pero no nos encierra de forma insuperable en un moral concreta. Nos sirve, además, para reproducir ese aprendizaje en relación con la moral de otras comunidades en las que, por las razones que sean, nos integremos.

Javier Muguerza (2007) aclara magistralmente este punto mediante una analogía: "Cuando aprendemos a hablar en nuestra lengua, lo que aprendemos es un lenguaje y no el lenguaje, de análoga manera a como aprendemos una moral y no la moral en cuanto tal. Pero, si nos fijamos bien, lo que aprendemos cuando aprendemos nuestra lengua es a comunicarnos lingüísticamente mediante ella y, por lo tanto, mediante cualquier otra que asimismo podamos aprender a partir de ella o desde ella; y algo muy semejante vendrá a ser lo que ocurra cuando aprendemos la moral de nuestra particular comunidad, a saber, que con ella aprendemos a comportarnos moralmente, aprendizaje que asimismo nos sería dado reproducir - a partir de esas experiencias y desde esas experiencias- en cualesquiera otras comunidades en las cuales podamos insertarnos o imaginarnos que lo hacemos" ${ }^{\prime \prime}$. En el fondo de esta posibilidad está operando la distinción que divulgó Aranguren $(1988)^{5}$, inspirado en la filosofía de Zubiri, entre "ética como estructura" y "ética como contenido".

Bajo este supuesto, lo que hoy sale a nuestro encuentro en un contexto mundializado no es de forma indefinida la cultura o la moral de "cualesquiera otras comunidades", como reza el texto citado, sino la concreta presencia simultánea de una pluralidad de formas de vida en los límites del Estado-nación, como hecho histórico irreversible y cualitativamente distinto a las migraciones de tiempos pasados $^{6}$; hecho al que denominamos con el término de "multiculturalismo". Esto nos exige -necesitados como estamos de convivir en la paz y el respeto mutuo- el diseño y aprendizaje de un punto de vista que no se imponga mediante su identificación con ninguna de esas formas de vida y que, por tanto, de alguna manera integre el sentido ético de todas ellas y mantenga en lo posible, de acuerdo con

4 J. MUgerzA (2007: 537).

5 J. L. L. ArANGuren (1988).

${ }^{6}$ Véase a este respecto R. ZAPATA-BARRERo (2008: 253-277). 
este proyecto, la aceptación positiva de las diferencias. Un lugar de encuentro, en fin, que nos permita ejercer una crítica racional de los particularismos morales y que consiga filtrar y depurar contenidos compartidos de lo que se ha acuñado entre los tratadistas como "Ética Mínima". Rubio Carracedo (2009) verbaliza y conceptualiza adecuadamente este proyecto utilizando prefijos muy expresivos en torno al hecho y el concepto de la "cultura", más allá de un simple juego de palabras: Propone, en efecto, alcanzar una "Ética Transcultural" a través de procesos "interculturales" que, superando los graves retos y dificultades generados por el "multiculturalismo", respeten el "pluralismo"s.

Así pues, el proyecto de una ética pública como "Ética Mínima" convoca, virtualmente al menos, a todos los hombres y mujeres de buena voluntad, sean cuales fueren sus creencias, en un mundo interconectado de cosmovisiones e intereses contrapuestos y recursos limitados, con objeto de buscar en común acuerdos, principios y normas que hagan posible la convivencia en libertad, paz y cooperación. Es decir, pretende despejar un horizonte ético incluyente del más amplio abanico de diferencias y cuyo único límite del obrar humano lo marque un sentido de humanidad ampliamente compartido. Es, pues, expresión de respeto y neutralidad hacia las distintas concepciones morales, aun cuando radicalmente contrario a la imposición de cualquiera de ellas con pretensiones de ostentar el monopolio de la verdad y la corrección moral.

En ese sentido, y sin olvidar los gravísimos incumplimientos pasados y presentes por parte de Occidente ni las serias críticas formuladas por filósofos de la sospecha y postmodernos 9 , es preciso reconocer que nuestras sociedades de democracia liberal, herederas de esa modernidad incumplida y justamente criticada, han construido un discurso que intenta aproximarse a la "Ética Mínima" y a la ética pública mencionadas, no sin grandes dificultades, luchas, tropiezos, incomprensiones, olvidos y aprendizajes a lo largo de su historia. Los miembros de dichas sociedades no podemos obviar dicho discurso, salvo que ofrezcamos mejores razones, puesto que formula el contrato moral y político que nos compromete.

\footnotetext{
7 Véase A. CORTINA (1986), la cual fue una adelantada en el planteamiento de esta temática en la obra que citamos y a la que precisamente dio el título de "Ética Mínima". También la parte I, puntos 1 y 2 , de H. KüNG (2000: 15-43), en donde se afirma que "la supervivencia es imposible sin una ética planetaria".
}

8 J. RuBio CARRACEDO (2009: 159-180), en el último capítulo de la obra señalada.

${ }^{9}$ Mientras G. VATTIMO y sus colaboradores (1990) definen el pensamiento posmoderno y J-F. LYOTARD (1989) su condición, P. RICOEUR (2003) ya había anunciado a los "filósofos de la sospecha". 
Tampoco se le puede negar su capacidad de hipótesis de trabajo para posibilitar el diálogo con otras culturas desde alguna parte y no desde un absurdo vacío de valores. En caso de someterlo a una especie de hipotético silencio, como algunos proponen, podría brindar la ocasión a poderosos discursos hoy en boga para ejercer una manipulación y una hegemonía de la que queremos huir. "No hay ética pública sin ideología, pero sí ideologías sin moral pública" ${ }^{10}$. Precisamente, desde esa capacidad de la modernidad, de sus valores e ideología, ha podido llevarse a cabo la crítica mencionada. Es, pues, necesario tener claros esos valores, abiertos siempre a la citada crítica, que es a la par autocrítica. Intentaremos ponerlos de relieve a continuación, siquiera sea con la brevedad de un fogonazo.

El punto de partida de la "Ética Mínima" lo constituye, como valor superior al que atenernos en nuestra conducta pública, la dignidad de la persona, es decir, la única instancia que potencialmente, en su propia racionalidad o de cualquier otra forma, puede aspirar a ser ampliamente compartida por hombres y mujeres de buena voluntad. El artículo 1 de la Declaración Universal de los Derechos Humanos así lo establece: "Todos los seres humanos nacen libres e iguales en dignidad y derechos y, dotados como están de razón y conciencia, deben comportarse fraternalmente los unos con los otros". E, igualmente, lo prescribe nuestra Constitución en el punto 1 del Título I (Art. 10), que trata "De los derechos y deberes fundamentales": "La dignidad de la persona, los derechos individuales que le son inherentes, el libre desarrollo de la personalidad, el respeto a la ley y a los derechos de los demás son fundamento del orden político y de la paz social". Y deja bien claro a renglón seguido, en el punto 2, que "Las normas relativas a los derechos fundamentales y a las libertades que la Constitución reconoce se interpretarán de conformidad con la Declaración de los Derechos Humanos". Partiendo de dicho principio fundamental de nuestra convivencia, Rubio Carracedo (2009) nos ofrece -en la obra citada- la quintaesencia de las normas que derivan de él: "el derecho a la vida, a la libertad, a las garantías básicas de seguridad individual y colectiva, al procesamiento legal, a la no discriminación por razón de etnia, sexo, edad o religión, al acceso a la educación, a los servicios mínimos de salud, a disfrutar de un medio ambiente sano, a no recibir trato vejatorio ni tortura, a emigrar por razones políticas o de subsistencia, así como a exigir derechos especiales para los discapacitados, los niños y los refugiados"11.

\footnotetext{
10 Por parecernos adecuada para lo que queremos expresar, nos valemos de la afirmación de J. GARCÉs (2006:103), pero modificada, sin cambiar la idea de fondo, para aplicarla a nuestro caso. La del citado autor dice textualmente así: "No hay bienestar sin ideología, pero sí ideologías sin bienestar".

${ }^{11}$ O.c.: p. 176.
} 
Como conclusión inicial, podemos afirmar, que ése es el ámbito de la ética pública en el que se legitima la necesidad del Estado de Derecho.

\section{2. Ética pública y formación ciudadana}

Nuestra comprensión de la ética pública expuesta, dado que no responde a inclinaciones innatas y para su justificación no le basta, en los tiempos que corren, la necesaria socialización en los valores de la comunidad de pertenencia, es más bien, como hemos adelantado, el resultado de un largo proceso histórico de debates teóricos y luchas sociopolíticas, siempre inconcluso. Proceso suficientemente conocido y documentado requiere, pues, aprendizaje en el ejercicio de una razón crítica, capaz de justificar o rechazar valores y normas morales universalizables de carácter público mediante argumentos de un rigor y una publicidad equivalentes en su orden de saber a los que desarrollan los conocimientos científicos.

El Estado de Derecho es un bien público en una sociedad plural, los principios y valores morales que orientan su labor no pueden surgir -utilizando la terminología de Kohlberg (1981: 409-412)- de un nivel de desarrollo de la conciencia moral "convencional", en el que los individuos se rigen por normas relativas a intereses o bienes no generalizables, propios de los colectivos particulares de pertenencia. $\mathrm{Ha}$ de ubicarse en el nivel "posconvencional", aquel en el que la conducta individual y las instituciones se legitiman por normas universales, atentas a las exigencias morales de todos los seres humanos. Es decir, por una formación Ética que englobe las condiciones de ser racional, dialógica, plural, mínima, pública, cívica y laica.

Y, sin duda, la concreción de estos valores depende de la creación de las condiciones sociopolíticas propias de una convivencia justa y ordenada. Aquella en la que cada persona y comunidad entren en la situación de ser respetadas por los demás para hacerse cargo, en la realización de su dignidad, del propio y diferenciado proyecto de vida. Corresponde, pues, al Estado garantizar dicho proceso formativo y aprendizaje, justificándose, en este sentido, la introducción, en nuestro país, en la enseñanza obligatoria de la Educación para la Ciudadanía. Hace mucho tiempo ya, recordaba insistentemente Aristóteles en la "Ética a Nicómaco" que si estudiamos ética no es por la curiosidad de saber sino para ser mejores.

En el punto anterior hemos planteado que la ética pública legitimadora del Estado de Derecho tiene como fundamento la "dignidad humana". Podríamos entender ésta como el "fundamento objetivo de la vida moral" en cuanto que es el objeto, 
el horizonte, la meta que ha de orientar nuestra conducta. Ante cualquier abanico de acciones en relación con nuestros semejantes en una situación dada la cuestión estriba en saber cuál de las alternativas se ajusta a ese objeto, si es que hay alguna que se ajuste, y cuál lo hace más y mejor. Pero también advertimos la necesidad de referirnos a nuestras elecciones, a nuestras responsabilidades, compromisos, aprendizajes, etc., es decir, a nuestra libertad. La libertad es, pues, el "fundamento subjetivo de la vida moral". Pero no de cualquier forma, sino en cuanto nos hace dueños de nuestra propia vida. Es decir, no sólo con respecto a interferencias y dueños externos, sino, sobre todo, en cuanto que nos libera de nuestras propias inclinaciones y nos permite actuar en relación con las que consideramos en virtud de argumentos las mejores propuestas practicables para ello. Ser libres, en este segundo sentido, es lo que llamamos "autonomía". Es lo que nos hace sentirnos como personas y tener dignidad. Y lo que nos lleva, junto con nuestros semejantes, a crear una convivencia sin dueños y sin más interferencias que las provenientes del respeto a la libertad de los demás. Es decir, a constituir el Estado de Derecho. La autonomía es, pues, como plantea Laporta ${ }^{12}$, el fundamento de dicho Estado.

Este conjunto de planteamientos reclama la concepción del ser humano como sujeto moral, asumiendo que "somos sujetos morales, pero no estamos sujetos a ninguna moral". Es algo, por supuesto, con lo que no nacemos, con lo que de alguna manera podemos llegar a sentirnos libres en relación con nuestra comunidad de socialización, que reclama aprendizaje, pero un aprendizaje que no se obtiene de una vez por todas, que ha de mantenerse alerta a los largo de nuestra vida, que es más una actitud orientada al saber que un estado de posesión de sabiduría. Y es una primera cuestión clave saber en qué consiste esa actitud. Carlos Thiebaut (1991) nos ofrece una clarificadora explicación de la misma: "no es la adhesión a una de esas moralidades particulares en uno de esos mundos concretos y diferentes lo que nos constituye en sujetos morales, sino que, por el contrario, somos más bien tales sujetos morales sólo cuando somos capaces de considerarnos reflexivamente ubicados en relación a otras formas de moral y a la nuestra misma, cuando podemos aprender y criticar otras morales en la medida en que podemos aprender y criticar la nuestra. Es decir, somos morales no tanto cuando seguimos un orden o una jerarquía de valores, cuando obedecemos un código determinado, sino cuando podemos ubicarnos en relación con ese código en una actitud que nos permite someterlo a crítica, hacerlo susceptible del procedimiento crítico de la razón, hacerlo reflexivo, en suma"13.

\footnotetext{
${ }^{12} \mathrm{Al}$ tema dedica todo el capítulo 1: "La autonomía personal".

${ }^{13}$ C. Thiebaut (1991: 203).
} 


\section{Estrategias políticas que vulneran la legitimidad del Estado de Derecho: Argumentos en defensa de la Seguridad Nacional}

En el marco del Estado de Derecho existe un juego de equilibrios entre seguridad, libertad, dignidad, en cuyos vaivenes se ve agitada la ciudadanía generando gran ansiedad en ella. En los últimos tiempos, se ha introducido también, en el debate político, el espectro del terrorismo internacional de carácter preferentemente yihadista y la llamada a la guerra global contra él, engañosamente planteada como enfrentamiento entre el bien y el mal. Una guerra que tiende a reproducir su dinámica en relación con otros grandes conflictos de orden político, social o cultural. Todo lo cual hace que la balanza, de la opinión pública, se incline a favor de la seguridad, evocándonos la dialéctica hegeliana del amo y el esclavo. Bien interpretaba Marx esta alegoría entendiendo que si el esclavo se somete a la voluntad del amo es porque tiene miedo a la muerte, concluyendo que, en último término, no es esclavo del amo sino de la vida. Pero, ¿̇qué vida puede valernos sin libertad, esa libertad que parecía prometernos el Estado de Derecho?

Además, convertir por obra y gracia de nuestros mandatarios, el terrorismo en un actor político más, justifica el todo vale contra él. Esto supone, no sólo declararle la guerra en el día a día como respuesta a sus agresiones, sino que la guerra preventiva allá donde se arbitre, puede esconder o camuflar el enemigo. También puede ser utilizada para la limitación de derechos y libertades a todo aquello que se mueva bajo el fantasma de lo sospechoso o tenga la mala fortuna de entornar comunitaria o culturalmente a lo sospechoso, sin tener en cuenta que con ello se expone a la gran mayoría de los inocentes de turno. ¿QQué queda, entonces, de seguridad y sentido democráticos a nuestras sociedades, y a nosotros como ciudadanos, si tan fácilmente se olvidan las garantías en el cumplimiento de los derechos humanos y se quebranta con total impunidad el Estado de Derecho?

Hoy las cosas no parecen estar tan claras, para los sistemas democráticos occidentales, a la hora de materializar este tratamiento políticamente. Hay varias causas que lo dificultan: en primer lugar, el demos, principal objeto de la atención política, definido hasta hace poco por el triángulo Estado-Nación-Ciudadano, ha sido rebasado en esos límites por la multiculturalidad. Hay que añadir, además, ciertos fracasos en el tratamiento de ésta (los graves episodios de terrorismo ocurridos: Torres Gemelas, Atocha, Metro de Londres...) y la actual crisis económica que afecta con mayor virulencia a los venidos de otros mundos. Todo ello ha hecho que la multiculturalidad se esté viendo como un peligro para nuestra forma de vida, generando un discurso negativo, el discurso del miedo, que parece imponerse cada vez más. 
La actual omnipresencia de los medios de comunicación, y muy en especial los que se valen del ciberespacio, pone de manifiesto que la "modernidad radical", referida por Giddens (1999), está compuesta de sociedades pensantes y, por tanto, sociedades pensadas; todo en ellas se convierte en objeto de comunicación y de reflexión, generando opinión pública. Los símbolos, las ideologías, los discursos políticos, ya no dependen sólo de la tradición, el poder o la autoridad moral, sino al menos también de los argumentos ${ }^{14}$.

En este sentido, consideramos que los argumentos utilizados por Bush II, en sus recientes memorias ${ }^{15}$, sobre las medidas de Seguridad Nacional adoptadas por él-muy a pesar suyo, según dice- en respuesta al terrorismo internacional, contribuyen a vulnerar la legitimad del Estado de Derecho. Argumenta que su pretensión era salvar vidas inocentes, y esto explica el esfuerzo de su gobierno por hacer que esas medidas se consideraran incluidas en el Estado de Derecho y dentro de la democracia. Por poner un ejemplo significativo, recordemos la respuesta del Departamento de Justicia a consultas de la CIA sobre la tortura. En ella se afirma que son inconstitucionales las leyes internacionales prohibiendo las torturas practicadas en la guerra de Bush como medida eficaz contra el terrorismo, porque se justifican en la prevención de nuevos ataques de Al Qaeda y son, por tanto, una afirmación de la vida. Desde esta perspectiva, lo que de verdad podría considerarse irresponsable e inconstitucional, sería desaprovechar la oportunidad de practicarlas con ese fin.

Hinkelammert(2005) ${ }^{16}$, de quien traemos el comentario precedente, añade que todo esto le recuerda "una anécdota que se cuenta sobre el Gran Inquisidor Torquemada del siglo XV. Este hizo un diálogo, en el cual se hace a sí mismo la pregunta: ¿̇Es lícito no torturar a un hereje? Y la respuesta: No es lícito no torturarlo porque con eso se le quita su última oportunidad de salvar su alma. Eso cambia ahora, aunque continúa. La pregunta en la actualidad dice así: èes lícito no torturar a un sospechoso de terrorismo? Y la respuesta: No es lícito no torturarlo, porque con eso se pierde la oportunidad de salvar vidas inocentes [...] Es Torquemada, secularizado. Este tipo de argumentos aparece por todos lados. Apareció también en relación con la bomba atómica sobre Hiroshima [...] El terrorismo del estado se hace pasar como un realismo humanista, verdadera afirmación de la vida humana".

\footnotetext{
${ }^{14}$ K. BAYERTZ (2003: 48).

${ }^{15}$ G. W. BuSH (2010).
}

16 F. J. Hinkelammert (2005: 7-10), disponible en http://www.pensamientocritico.info/articulos/ articulos-de-franz-hinkelammert/109.html. 
Nos atenemos a las explicaciones de Elías Díaz (2002), uno de nuestros mejores tratadistas del Estado de Derecho, para disipar todo tipo de dudas al respecto: "El Estado no puede, no debe, de ningún modo, responder al delito con el delito, a la violación de la ley por el delincuente con la violación de la ley por el gobernante o sus representantes: alegando una supuesta eficacia, se convertiría así en un Estado delincuente. No puede, ni debe, cometer el gravísimo delito y el gravísimo error de, por ejemplo, intentar acabar con el terrorismo implantado por unas $u$ otras bandas o asociaciones armadas cayendo en un correlativo terrorismo de Estado ejercido o ayudado ilegalmente por las legítimas instituciones y tal vez con cierto apoyo social. Si tal hiciera, pondría en cuestión su propia legitimidad: por acogerse a la razón de la fuerza perdería la fuerza de la razón. El delito y la violencia contra el sistema jurídico y políitico de libre participación, deben ser en todo caso contestados, perseguidos y dominados precisamente desde esa misma legalidad que aquéllos violan, atacan o pretenden destruir: ¿qué diferencia habría si ambas partes la niegan $y$, en este sentido, la menosprecian por igual? La mejor defensa de la legalidad exige actuar siempre dentro del marco de la Constitución y el Estado de Derecho. No sólo esto es más justo y más legal, sino que incluso tanto a corto como a medio y largo plazo, preocupándose por contar con adhesiones sociales más fundadas e ilustradas, será además mucho más eficaz para todo el sistema político y social. El Estado de Derecho es, pues, el imperio de la ley"17.

¿Cuáles son, pues, la claves de esta forma de pensar, que nos muestra una peligrosa capacidad para ganar adhesiones más o menos conscientes o explícitas? Hinkelammert, en el artículo citado, nos ayuda a desvelarlas. Ofrecemos a continuación muy sucintamente las principales líneas de su planteamiento.

El punto de partida para entender esta falsificación del Estado de Derecho se sitúa en la estrategia de la globalización que, valiéndose de las nuevas tecnologías, a quien beneficia de verdad es a los "mercados globales en manos de grandes burocracias privadas de empresas transnacionales", convirtiendo a los gobiernos en sus servidores. Lo estamos viendo en la presente crisis. La hegemonía de esta estrategia induce en la población mundial gravísimos quebrantos en relación con los derechos humanos, la supervivencia y la exclusión, además de agravar los problemas del medioambiente. Pero las medidas sociales -el Estado Social-para paliar dichos males son consideradas como "distorsiones del mercado". Es distorsión también controlar los movimientos de capitales y mercancías, pero no lo es controlar, incluso de forma violenta, los movimientos de las personas. Esto a su vez

${ }^{17}$ E. DíAz (2002: 83, s.). 
provoca en la sociedad civil de los países desarrollados y en comunidades con gran fuerza identitaria vivas reacciones que sintetizamos en dos líneas fundamentales de actuación: por una parte, los movimientos alternativos, de temple pacifista, a favor de la vida a través de cambios en el sistema, impulsados por la convicción de que "un mundo mejor es posible"; $y$, por otra, los movimientos del fanatismo violento y apocalíptico que recurren al terrorismo para imponer su hegemonía.

No obstante todo esto, los protagonistas de la estrategia de la globalización sostienen que no hay alternativa ${ }^{18}$ al sistema capitalista de mercado neoliberal, manteniéndose inflexibles mientras exigen la máxima flexibilidad a todas las demás instancias ${ }^{19}$. Y a ello se enfrentan recogiendo para sus fines de ambos movimientos de reacción sus características más relevantes: de los alternativos adoptan su ideal, la defensa de la vida; de los terroristas, sus procedimientos violentos. Lo hacen manteniendo el disfraz del Estado de Derecho y la democracia, bajo cuya apariencia se sienten legitimados a declarar la "guerra al terrorismo". Se trata de una democracia reducida a votación y, hasta donde sea posible, manipulada mediante argumentos fraudulentos basados en cosmovisiones de tufo totalitario, con capacidad para estimular el fanatismo, las más absurdas creencias y el temor en la ciudadanía. Argumentos que, en síntesis, se reducen a escenificar la situación como la lucha entre el Bien y el Mal.

De esta forma, la guerra preventiva salva vidas, la declaración de la guerra al terrorismo salva vidas, el Sistema de Seguridad Nacional salva vidas, la tortura salva vidas, la estrategia globalizadora capitalista de orientación neoliberal salva vidas. En este último punto, no nos resistimos a transcribir, una reflexión verdaderamente estremecedora de Hayek, que asimismo aporta Hinkelammert en el lugar citado (nota 6) 20: "Una sociedad libre requiere de ciertas morales que en última instancia se reducen a la mantención de vidas: no a la mantención de todas las vidas porque podría ser necesario sacrificar vidas individuales para preservar un número mayor de otras vidas. Por lo tanto las únicas reglas morales son las que llevan al cálculo de vidas: la propiedad y el contrato".

\footnotetext{
${ }^{18}$ Significativamente, su lema es TINA: "There is no alternative". (En artículo de F. J. HinkELAmmerT).

${ }^{19}$ Prueba palmaria de ello la tenemos con la actual crisis en el hecho de que los mercados no perdonan la deuda contraída con ellos y exigen a los demás, que suelen ser los menos responsables de la situación, de forma insaciable todos los sacrificios que sea necesarios para saldarla o merecer su confianza.

20 La cita de F. HAYEK se encuentra en una entrevista publicada en "El Mercurio", Santiago de Chile, 19/04/81. La expresamos en cursivas para diferenciarla de las citas literales a F. J. HiNKELAMMERT.
} 
En el mismo sentido, consideramos que las declaraciones de Felipe González sobre "su" responsabilidad política cuando era presidente del gobierno y que aparecen en una entrevista que le hizo Juan José Millás ${ }^{21}$, contribuyen a vulnerar, en buena medida, la legitimidad del Estado de Derecho.

En este caso, la entrevista revela que el protagonista, siendo Presidente y en torno a los años 1989-1990, recibió información fidedigna de la hora y el lugar de una reunión de la cúpula de ETA. Y comenta: "En aquel momento solo cabía la posibilidad de volarlos a todos juntos en la casa en la que se iban a reunir. Ni te cuento las implicaciones que tenía actuar en territorio francés, no te explico toda la literatura, pero el hecho descarnado era: existe posibilidad de volarlos a todos y descabezarlos. La decisión es sí o no. Lo simplifico: dije no". Pero, a continuación, manifiesta algo que es lo que nos interesa destacar: "Y añado a esto: todavía no sé si hice lo correcto". Esto último, volvió a repetirlo públicamente, días más tarde de la citada entrevista, encontrándose en Colombia ${ }^{22}$. Semejante dilema, mantenido a lo largo de veinte años según él mismo confesó, nos parece que, explicitado en los medios de comunicación, vulnera la legitimidad del Estado de Derecho.

A primera vista, sus inquietudes, tal y como se muestran en el discurso, parecen encomiables, propias de una persona dotada de sensibilidad humana y sensatez política. Él, desde luego, no las habría expresado en público reiteradamente si no esperara que fueran a producir consecuencias en la sociedad española.

Desde nuestro análisis, consideramos que esas dudas se sustentan en un grave error político. El error está en olvidar que la responsabilidad del poder delegado en sus manos por los ciudadanos es para ejercerlo no de forma arbitraria o pendiente de pálpitos y ansiedades personales sino dentro de los límites legales que marca el Estado constitucional de Derecho. Y ése es el juramento que se le exige cuando asume su cargo.

Felipe González incurre en la ambigüedad en la que, según Laporta ${ }^{23}$, incurrió Carl Schmitt para justificar el uso del poder de un régimen totalitario: la de no distinguir el poder "fáctico" de "hacer una cosa en el mundo real", del poder "normativo" con el que se expresa "que no tienen permiso para hacerlo, que no deben hacerlo, que

\footnotetext{
${ }^{21}$ El País, 07-11-10.

${ }^{22}$ CERESTV.INFO, disponible en http://www.youtube.com/watch?v=-bU7SnvHBlg\&feature=related.

${ }^{23}$ O.c.: p. 72.
} 
está prohibido que lo hagan en virtud de la regla que se expresa en ese enunciado. $Y$ eso no tiene lógicamente nada que ver con que algo pueda o no suceder en la realidad externa". Aquí no hay dilema para un presidente de gobierno de un Estado de Derecho elegido democráticamente. Felipe González duda de si acertó o no acertó en la decisión tomada. De lo que no duda -y esa es la cuestión de nuestra crítica- es de que volar la cúpula de ETA era una alternativa para él. Pero se equivoca porque no hay situación alguna que convierta en alternativa legítima el quebrantamiento del Estado de Derecho.

Expresado esto en unos impecables términos kantianos, Felipe González no actuó "contra el deber", puesto que decidió no dar la orden de volar la cúpula de ETA y, por tanto, actuó "conforme al deber", pero no "por deber". No hacemos juicios de intención; él mismo lo pone de manifiesto.

Así pues, la manifestación de las citadas dudas es muy preocupante. Felipe González ha sido durante catorce años Presidente del Gobierno, goza internacionalmente de un merecido prestigio político y una gran autoridad moral, en estos últimos tiempos, en fin, el Consejo de Europa le nombró Presidente del "grupo de sabios" encargado de definir el futuro de la Unión Europea a partir del 201024, etc. Lo que diga un personaje con este reconocimiento contribuye en gran manera a generar pensamiento y opinión pública, a crear, sin duda, realidad por lo que hace a la garantía de nuestros derechos y libertades.

Nadie que esté al corriente de lo que sucede, no ya fuera sino en el mismo recinto de nuestras democracias liberales, ignora alguna de las graves violaciones, que se van desvelando paulatinamente ${ }^{25}$, a nuestros Estados constitucionales de Derecho, en relación con los derechos civiles, políticos y sociales: campos de prisioneros, torturas sistemáticas, desaparición de personas, muerte, abusos y arbitrariedades a la población civil, ocultación de datos al respecto y, sobre todo, guerra preventiva contra el terrorismo o lo que gente interesada defina por su cuenta como tal. Es preciso estar alerta y sospechar de cualquier discurso que justifique dichas acciones $^{26}$.

En este contexto, por muy diferentes que sean las situaciones, las dudas de González y las decisiones de Bush, vulneran claramente la defensa de nuestros Estados de

${ }^{24}$ El País, 14-12-07.

25 Recordemos las últimas revelaciones vertidas en la red Wikileaks.

26 Rescatando la actitud crítica de los mencionados "maestros de la sospecha". 
Derecho. Y, tomando pie de la cita de Elías Díaz, para nada se preocupan por algo que es sumamente necesario fomentar por personas de prestigio: las "adhesiones sociales más fundadas e ilustradas", "mucho más eficaces para todo el sistema político y social" que cualquier otro apoyo.

Entendemos que los motivos que argumentan no son exclusivos de personas aisladas, sino que sus discursos tienen una clara conexión argumental con otros más globales que justifican el terrorismo de estado bajo la premisa de seguridad nacional y como una estrategia necesaria para la defensa de la vida de inocentes. Sean sus portadores conscientes o no de ello, esos motivos se engarzan en una corriente de pensamiento que cada vez va adquiriendo más fuerza en la opinión pública. Las ideologías pueden infiltrarse, a través de discursos convencionales, sin percatarnos de ello en nuestras interpretaciones de la realidad.

A la vista de todo esto, no cabe si no reconocer las garantías que ofrece la fidelidad al "Estado social y democrático de Derecho" consagrado en nuestra Constitución, conscientes de la obligación y la necesidad que tenemos de defender una institución de la convivencia que tanto nos ha costado construir y que salva vidas de verdad. Es, pues, necesario, reconstituir el nuevo demos político y restablecer el discurso positivo "con una políticas de ciudadanía encaminadas a que todas las culturas asuman unos mínimos valores compartidos que canalicen bajo el término de civismo" 27 .

Así pues, Kant, además de otras contribuciones, nos legó la inmensa enseñanza - quizá una de las más importantes que hemos recibido- de que los seres humanos, y los pueblos, no son simples objetos fenoménico-empíricos sobre los que tener un conocimiento y ejercer un uso irrestricto, sino que forman "un reino de fines en sí, coligado por la ley moral, es decir, por esa constitución anterior a toda constitución política. Tienen dignidad y no precio, deben tomarse siempre de manera que quede a salvo su condición de fines en sí mismos" ${ }^{\prime 28}$. Quizá la decantación de esta propuesta en nuestra cultura podría consistir en considerar, la Declaración de los Derechos Humanos, integrados en muchas de nuestras Constituciones, como valores superiores o leyes fundamentales. Por supuesto, seguimos hablando de leyes y de Estado de Derecho, porque, como Kant una vez más, nos damos cuenta de lo que él mismo dijo: que "la moral sin derecho coactivo es tan ineficaz para

${ }^{27}$ R. ZAPATA-BARRERO (2008: 275).

${ }^{28}$ Reflexión recogida en el artículo de J. Gómez CAFfarena (1996: 66 y 67). 
socializarnos pacíficamente como el agua de rosas para curar tumores"29. Pero, eso sí, se trata de leyes que nos garantizan derechos y libertades.

\section{Conclusiones}

Llegamos a la conclusión final defendiendo la convicción de que en el contexto actual el Estado de Derecho debe ser reforzado desde los contenidos de la ética pública que legitima su existencia, es decir, desde:

\section{a) La mediación de una razón moldeada por la formación ciudadana}

Las voluntades individuales, colectivas y/o de los poderes públicos, están sometidas a las capacidades internas (querer, preferir...), pero también a causas externas que a lo largo de la historia han ido cambiando. La consolidación del Estado de Derecho obliga a los responsables políticos y a los ciudadanos a actuar responsablemente reflexionando sobre las consecuencias de nuestras acciones $v$ omisiones. Ser dueños y responsables de las acciones, en el contexto del Estado de Derecho, significa saber y argumentar los motivos por los que contraemos determinadas obligaciones morales, es decir, que nos capaciten para justificar las razones favor o en contra de realizar una acción. Entendemos, por ello, que es preciso formar y formarnos para generar en nuestras sociedades valores compartidos de adhesión a la convivencia pacífica y de rechazo a la justificación de la violencia como forma de resolución de conflictos.

b) Una razón pública que garantice unos derechos mínimos para todas las personas

La ética no queda remansada al ámbito privado, está inmersa en el ámbito de lo público porque es constitutivamente social. Como tal, apela a criterios externos a la propia conciencia, para poder decidir qué conductas y qué comportamientos son aceptables o no desde el punto de vista ético.

La ética pública apela a los deberes y obligaciones que contraemos todas las personas que formamos parte de una comunidad social y política.

${ }^{29}$ F. ReQuejo Y R. Valls (2007: 129). 
Desde el punto de vista ético podemos considerar el Estado de Derecho como un proyecto público que regula los derechos y obligaciones de la ciudadanía, estableciendo unas garantías mínimas. Dicho proyecto no es algo acabado sino que es revisable desde un constante diálogo encaminado a defender la lucha por la defensa de la dignidad humana.

c) Una razón dialógica y crítica orientada a la defensa de la vida humana.

La razón dialógica se construye y de-construye a través de los discursos y las prácticas. La fuerza que adquieren los discursos utilizados por los responsables políticos sobre la seguridad nacional, se convierten en estrategias puestas en juego para influir en las conductas de los ciudadanos a través de argumentos basados en la combinación de datos, razones y sentimientos. Los Estados no pueden permanecer neutros o ausentes ante los envites provocados por los discursos que justifican la "seguridad nacional" y el uso de procedimientos que responden al viejo precepto de "ojo por ojo y diente por diente".

La utilización de argumentos orientados a la defensa de la vida humana sin restricciones nos beneficia a todos como ciudadanos y como personas.

\section{Referencias bibliográficas}

Aristóteles (1981) Ética a Nicómaco. Madrid: Centro de Estudios Constitucionales.

Aranguren, J. L. L. (1988) Ética. Madrid: Alianza.

BAYERTZ, K. (2003) "La moral como construcción. Una autorreflexión sobre la ética aplicada", en CoRtinA, A. y García MARZÁ, D. (eds.) Razón pública y éticas aplicadas. Madrid: Tecnos, pp. 47-69.

Bush, G. W. (2010) Decision Points. New Cork: Crown.

CerESTV.INFO (2010) "González vuelve a dudar de si acertó al negarse a eliminar a la cúpula de ETA en los años 80". Disponible en http://www.youtube.com/ watch? $v=-b U 7$ SnvHBlg \&feature=related.

Cortina, A. (1986) Ética mínima. Madrid: Tecnos. 
CORTINA, A. (2010) "Neuroética: ¿̇las bases cerebrales de una ética universal con relevancia política?", Isegoría, n. 42, pp. 129-148.

DíAz, E. (2002) "Estado de Derecho y legitimidad democrática", en DíAz, E. y CoLOMER, J. L. (eds.) Estado, justicia, derechos. Madrid: Alianza, pp. 75-104.

Garcés, J. (2006) "Política social e ideología", en Alemán, C. y Fernández, T. (coords.) Política Social y Estado de Bienestar. Valencia: Tirant lo Blanch, pp. 103-133.

GIDDENS, A. (1999) Consecuencias de la modernidad. Madrid: Alianza.

GÓMEZ, C. (1996): "La religión como universo simbólico". Revista de filosofía, n. 85, pp. $62-87$.

- (2007) "Una reivindicación de la conciencia (De la crítica a la filosofía de la conciencia a la reivindicación de la conciencia moral)", Isegoría, n.36, pp. 167-196.

HINKELAMMERT, F. J. (2005) "La transformación del estado de derecho bajo el impacto de la estrategia de globalización", disponible en http://www.pensamientocritico. info/ articulos/articulos-de-franz-hinkelammert/109.html.

KANT, I. (1996) Crítica de la razón práctica. Salamanca: Sígueme.

KOHLBERG, L. (1987): "Apéndice I. Los seis estadios del juicio moral" (versión íntegra), en RUBio CARRACEDO, J.: El hombre y la ética. Barcelona: Anthropos, pp. 219-224.

Küng, H. (2000) Proyecto de una ética mundial. Madrid: Trotta.

LAPORTA, F. J. (2007) El imperio de la ley. Una visión actual. Madrid: Trotta.

LYOTARD, J-F. (1989) La condición postmoderna. Informe sobre el saber. Madrid: Cátedra.

MARX, K. (1975) "Introducción general a la crítica de la economía política", en MARX, K. y Engels, F. Obras escogidas. Barcelona: Fundamentos.

MiLÁs, J. J. (2010) "Entrevista: Felipe González. Tuve que decidir si se volaba a la cúpula de ETA. Dije no. Y no sé si hice lo correcto". El País. Madrid, 07-11-10. 
Missé, A. (2007): "Felipe González presidirá el 'grupo de sabios' de la UE". El País. Madrid, 14-12-07.

MuguerzA, J. (2007) "Ética pública, derechos humanos y cosmopolitismo", en GóMEZ, C. y MUGUERZA, J. (eds.) La aventura de la moralidad (paradigmas, fronteras y problemas de la ética) Madrid: Alianza, pp. 510-549.

Requejo, F. y VAlls, R. (2007) "Somos conflictivos, pero... Actualidad de la tesis de Kant sobre la insociable sociabilidad de los humanos y su prolongación por parte de Hegel", Isegoría, n. 37, pp. 127-163.

RiCOEUR, P. (2003): El conflicto de las interpretaciones. Ensayos de hermenéutica. Buenos Aires: Fondo de Cultura Económica.

Rubio Carracedo, J. (2009) Ética del siglo XXI. Barcelona: Proteus.

SANTA CRUZ, L. (1981) "Entrevista a Friedrich von Hayek: de la servidumbre a la libertad". El Mercurio, Santiago de Chile, 19-04-81.

Thebaut, C. (1991), "¿La emancipación desvanecida?", en Thiebaut, C. (ed), La herencia ética de la llustración. Barcelona: Crítica, pp. 198-218.

VATtMo, G.; MARDONes, J. M.; URDANABIA, I.; et al. (1990) En torno a la posmodernidad. Barcelona: Anthropos. Barcelona.

ZAPATA-BARRERO, R. (2008) "Multiculturalidad, inmigración y democracia: la reconstrucción del demos político", en QUESADA, F. Ciudad y ciudadanía. Senderos contemporáneos de la Filosofía Política. Madrid: Trotta, pp. 253-277. 